\title{
Addressing Communications Campaign Development Challenges to Reduce Stunting in Indonesia
}

\author{
Cougar Hall ${ }^{*}$, Ahmad Syafiq ${ }^{2}$, Benjamin Crookston${ }^{1}$, Cudjoe Bennett ${ }^{3}$, Muhamad R. Hasan ${ }^{4}$, \\ Mary Linehan ${ }^{3}$, Joshua West ${ }^{1}$, Scott Torres ${ }^{3}$, Kirk Dearden ${ }^{5}$ \\ ${ }^{1}$ Department of Public Health, Brigham Young University, Provo, Utah, USA \\ ${ }^{2}$ Faculty of Public Health, Universitas Indonesia, Depok, Indonesia \\ ${ }^{3}$ IMA World Health, Washington DC, USA \\ ${ }^{4}$ IMA World Health, Jakarta, Indonesia \\ ${ }^{5}$ IMA World Health, Dares Salaam, Tanzania \\ Email: *coughall@gmail.com
}

How to cite this paper: Hall, C., Syafiq, A., Crookston, B., Bennett, C., Hasan, M.R., Linehan, M., West, J., Torres, S. and Dearden, K. (2018) Addressing Communications Campaign Development Challenges to Reduce Stunting in Indonesia. Health, 10, 1764-1778.

https://doi.org/10.4236/health.2018.1012133

Received: November 21, 2018

Accepted: December 24, 2018

Published: December 27, 2018

Copyright (c) 2018 by authors and Scientific Research Publishing Inc. This work is licensed under the Creative Commons Attribution International License (CC BY 4.0).

http://creativecommons.org/licenses/by/4.0/

\begin{abstract}
One in four children under 5 years of age in the developing world are stunted (chronically malnourished). Reducing stunting can be a challenge, especially in populous countries where families are dispersed, as is the case in Indonesia. This paper describes how one government project (Indonesia's National Nutrition Communication Campaign [NNCC]) delivered effective behavior change communications interventions that reached 40 million people. This paper focuses on four challenges that nutrition campaigns often face and provides useful lessons for similar campaigns, based on the experience of NNCC, which include the following: 1) Fully engaging stakeholders at all levels in campaign design and implementation ensured broad-based support for stunting reduction efforts; 2) Pro-actively involving journalists in nutrition campaigns improved public opinion about stunting and positively influenced decision-making in policy formulation; 3) Use of humorous public service announcements with limited technical information was effective in engaging priority populations; and 4) Social media (YouTube ads, web advertorials, Facebook pages, Twitter, Instagram) extended the campaign's reach and reinforced messaging from other sources. Based on NNCC's experience, specific recommendations are provided.
\end{abstract}

\section{Keywords}

Global Health Promotion, Stunting, Indonesia, Communications Campaign 


\section{Introduction}

Stunting (chronic undernutrition: the proportion of children $<5$ years old whose height-for-age is $<-2$ standard deviations of the reference population median) is one of the best overall indicators of children's well-being [1]. It accurately reflects social inequalities, is a marker of multiple pathological disorders, signals possible increased morbidity and mortality, and suggests that children may be at risk of poor developmental and cognitive function and chronic diseases in adulthood [2]. Despite its importance, stunting remains unacceptably high. In 2016, 22.9\% of children $<5$ years old in the developing world were stunted [3]. Risk factors for stunting include birth risks (poverty, maternal age and education, parity, birth spacing, and maternal malnutrition) and birth outcomes (small-for-gestational age, pre-term), sub-optimal feeding, diarrhea, wasting, and household food insecurity [4] [5] [6].

Indonesia reduced the proportion of malnourished individuals (regardless of age) from 20\% (1999) to below nine percent (2013). In Indonesia, the prevalence of stunting among children $<5$ years is $37.2 \%$ while cross provinces, stunting ranges from $23 \%-58 \%$ [7].

Stunting is reduced with healthy eating behaviors, good hygiene, use of latrines and clean water, sanitary environments and adequate healthcare. For example, consumption of fruits, vegetables, and animal source foods is associated with large reductions in stunting [8] [9]. Healthy hygiene practices and sanitation, including keeping toddlers away from exposure to and ingestion of animal feces, reduce environmental enteropathy which is associated with poor growth [10]. Improving hygiene and sanitation have about the same impact on stunting as the best infant feeding programs, though the impact may be small [11] [12].

A package of interventions that includes management of acute malnutrition, infant and young child feeding (IYCF), and micronutrient supplementation, has the potential to reduce stunting by $>20 \%$ [4]. Social and behavior change communications (SBCC) interventions include interpersonal communication (e.g., one-on-one counseling and support groups), mass and mid-sized media (e.g., community radio), and community and social mobilization.

A review of mass media's impact on child survival found that among 32 child survival evaluations deemed methodologically rigorous, 26 showed positive impact of mass media on self-reported behaviors, including nutrition-related behaviors [13]. The authors noted a publication bias in favor of successful communications campaigns [13].

\section{Context}

Indonesia is the largest economy in Southeast Asia with a gross domestic product growth rate of 5\% annually (2010-2016) [14] [15]. It is the third largest democracy and the fourth most populated country in the world [16]. A growing middle class increasingly seeks private sector health services [17].

Indonesia's government decentralized in 1999. Health services devolved to 
district governments. Decentralization has not resulted in services that are more responsive to local conditions and variations in malnutrition [18].

Indonesia is part of the Scaling Up Nutrition (SUN) movement-an initiative designed to eliminate malnutrition by 2030-which has prioritized stunting reduction. With support from the Millennium Challenge Corporation (MCC) and the Millennium Challenge Account-Indonesia (MCA-Indonesia), the Government of Indonesia designed and implemented interventions through the Community-based Health and Nutrition Project (CHNP) to prevent and reduce low birth weight, childhood stunting, and under-nourishment among children, including a National Nutrition Communication Campaign (NNCC). A government initiative supported by IMA World Health and partners, the NNCC raised awareness about stunting and changed individuals' behaviour through media, interpersonal communication, and community and social mobilization. NNCC worked with multiple ministries at national, regional, district, and community levels to strengthen government commitment to stunting reduction. At the district level, NNCC mobilized local coalitions to increase support for stunting reduction, including stakeholder meetings; seminars and public discussions; hearings with local parliament; and development and distribution of advocacy tools. NNCC involved local and regional decision-makers in television and radio talk shows. Once convinced to participate, government staff paid greater attention to stunting. Government staff were persuaded to address stunting as a result of increased community knowledge and demand for government response. NNCC used media, interpersonal communication, and community and social mobilization to increase knowledge, change social norms, and improve nutrition-related practices. Media included a mass media campaign, coupled with mid-sized media (local radio, editorials), small media (banners, infographics, interactive photos), and social media (Facebook, Twitter, Instagram, YouTube). Television spots on highly-rated TV programs were used. Additionally, NNCC educated journalists about stunting's importance and severity in addition to interventions for stunting reduction via partnership with local journalists' associations. NNCC's innovative use of social media was informed by tracking trending issues and research to identify nutrition issues of interest to internet users. NNCC purchased Facebook ads to increase traffic. High viewership ratings for YouTube ads and web advertorials demonstrated interest in the topic of stunting. NNCC linked cross-platform content (NNCC websites, Facebook, Twitter, Instagram, YouTube); and promoted "off-air" activities, including one-on-one counselling and support groups. The NNCC was implemented from November 2015 to March 2018, covering 11 districts in South Sumatra and West and Central Kalimantan provinces, to improve behaviors related to stunting reduction. NNCC is the Government's first national campaign since decentralization to reduce stunting and reached 40 million people through national television.

\section{Challenges and Useful Practices}

Here, we focus on four challenges nutrition campaigns often face: engaging 
stakeholders, engaging journalists, adapting messages, and utilizing media. We also present useful practices for overcoming these challenges based upon the experiences of NNCC. These insights may be particularly valuable to middle-income countries with large populations where governments do not recognize nor prioritize stunting reduction-as was the case among non-health ministries in Indonesia for some levels of government. These practices may also be relevant to public health domains other than nutrition.

A lack of forthrightness about challenges prevents policy makers and program planners, implementers, and evaluators from designing and implementing effective campaigns. We present the following four challenges together with useful practices based upon our experience with NNCC. We describe specific efforts and lessons learned within the NNCC context and provide key recommendations for future programs.

\subsection{Engaging Stakeholders}

A significant challenge is that often the appropriate stakeholders are not involved in campaign design, implementation, and evaluation. A useful practice for meeting this challenge is to fully engage stakeholders at all levels in campaign design and implementation to ensure broad-based support for stunting reduction efforts.

NNCC worked in close collaboration with donors and the Ministry of Health $(\mathrm{MOH})$ to align its objectives and activities with the National Food and Nutrition Action Plan. Additionally, NNCC built on commitments the government of Indonesia had made as part of the SUN initiative and helped advocate for larger budget allocations for nutrition interventions at national, district, and village levels. NNCC helped the provincial planning agency (Bappeda) review and provide technical support to the District Action Plan for Food and Nutrition. Previously, NNCC also advocated for Bappeda's support, prior to approaching district governments.

At the district level, NNCC worked with three district-level institutions (the District Planning and Development Bureau, the District Health Services [DINKES], and the District Community Empowerment Bureau). Using a participatory approach, NNCC established steering committees under the leadership of the DINKES Health Promotion Manager which served as the coordinating structure to plan, design, and implement the campaign. NNCC helped district governments develop local frameworks for including nutrition in health programs, including plans and strategies for advocating with local (and national) parliaments to prioritize stunting reduction in policy and resource allocation. NNCC supported and collaborated with existing government and community structures and facilities such as the district health office (DHO), Bappeda, Puskesmas (sub-district health center), and Posyandu (integrated health service post) to organize stakeholder meetings that involved government and non-government actors working in nutrition; water, sanitation, and hygiene (WASH); agriculture; 
and infrastructure. Engagement with multiple stakeholders was a continuous process throughout the life of the campaign.

Engaging the government was a way of preparing messaging for politicians that they then used to advocate for policy change, including influencing constituent behavior. Additionally, NNCC advocated locally with village chiefs, informal leaders, and sub-district leadership prior to implementing outreach activities, and by doing so, secured local leaders' commitment to reduce stunting, including through the allocation of additional funds.

Key Recommendations. To promote the success and sustainability of nutrition campaigns, implementing partners should ensure that their work is consistent with large-scale government programs, national nutrition action plans, and global commitments such as the SUN movement initiative. Implementing partners should also consider: 1) strengthening local committees; 2) guaranteeing that steering committees are under the leadership of local government; 3) ensuring that committees include health and non-health sectors; and 4) capitalizing on participatory approaches to involve all stakeholders.

\subsection{Engaging Journalists}

A key challenge is that journalists may not recognize the importance of nutrition and fail to raise the issue of stunting, or to accurately represent the issue. A useful practice in addressing this challenge is to engage journalists in nutrition campaigns to improve public opinion about stunting and to positively influence decision-making in policy formulation.

Journalists can be an effective means of disseminating correct information about topics that are poorly understood, as was the case with stunting in Indonesia. The Indonesian government had already successfully engaged the media as part of its work on HIV/AIDS; thus, pursuing a similar approach for stunting held considerable promise. These efforts included training journalists to report correct information on HIV, collaboration between National and Provincial AIDS committees and Civil Society Organizations to raise the profile of their HIV response in national and local media, improving both the quantity and quality of media reports on HIV, and strengthening capacity to involve media in news coverage.

As part of its larger effort to reduce stunting in Indonesia, NNCC carried out numerous activities to increase exposure to the concept of stunting, what causes it, and what can be done to address it. In addition to the use of mass media (television), NNCC implemented mid-sized media activities that actively involved the press. These efforts encompassed much more than simply informing media of events that publicize stunting. Specifically, NNCC: 1) worked with local journalists' associations to set the media agenda for stunting reduction; 2) conducted media visits to maintain strong ties with the local press; 3) participated in journalist forums to keep stunting high on the media's agenda; and 4) trained journalists. Training aimed to educate journalists on stunting, provide statistics and 
facts about it, raise awareness, and introduce journalists to counterparts at the province and district levels.

Working with local journalists' associations, media visits, participation in journalists' forums, and training of journalists strengthened the media's understanding of stunting. More importantly, these activities improved the public's understanding of this issue which, in turn, may have influenced the policy and decision-making process by creating a groundswell of support for nutrition action. Such efforts also raised the visibility of stunting in the national media, including news and articles about stunting. Between November of 2015 and December of 2017, 134 articles were published, including many newspaper reports.

Key Recommendations. Consider engaging media more fully-through collaboration with journalists' associations, media visits, the training of journalists, and other activities-to raise the visibility of stunting, change communities' understanding of it, and create a groundswell of support for policy change.

\subsection{Adapting Messages}

An additional challenge is that campaign messages can become overloaded with too much technical information that is not emotionally appealing. A useful solution is to use humorous public service announcements to engage the priority populations and limit the number of spots that only convey technical information.

Appropriate messaging is critical to the success of large-scale, integrated nutrition campaigns. When used effectively, messages create awareness of issues such as stunting, improve individuals' understanding of that issue, and increase the likelihood that individuals will commit to adopting optimal practices. Messages can also reduce barriers to adopting those practices.

SBCC is designed to convert technical information about health into easy-to-understand messages in a way that increases the likelihood of behavior change. The number and content of messages campaigns use matter. Given that reductions in stunting come about through the adoption of multiple behaviors related to diet, infection, and caregiving, often, efforts encourage individuals to adopt a variety of complex behaviors. However, it is possible to "overload" campaigns with too many messages promoting difficult-to-adopt practices.

Campaigns often draw upon the experience of initiatives carried out elsewhere because of the demonstrable success of those messages on knowledge, attitudes, and behavior change. Additionally, staff are keen to maintain consistency with the messages governments and international bodies promote such as those found in UNICEF's infant and young child feeding counselling package, Facts for Life, and so on.

NNCC worked with the $\mathrm{MOH}$ (including provincial and district levels), Bappenas, donors (including MCA-Indonesia), and media partners, to select appropriate messages for Indonesia. This was done, in part, via a thorough review of the program literature to identify what messages might work locally. Thus, many 
of NNCC's messages were based on demonstrably effective messaging from other large-scale, integrated nutrition programs.

In collaboration with Univeritas Indonesia, NNCC conducted formative research to document people's understanding of stunting and to identify factors influencing their practice of appropriate behaviors. Challenges identified through NNCC's formative research included low prevalence of exclusive breastfeeding, frequent use of infant formula (due, in part, to mothers' work outside the home), early introduction of solid foods; lack of diversity in the foods children ate, unhealthy snacks before meals, a laissez faire attitude toward caregiving, lack of availability of soap and improved water, mothers' lack of understanding of the importance of stunting, "eating down" in the first months of pregnancy because of morning sickness, lack of counselling on nutrition during antenatal care, and lack of male involvement in caregiving.

Thereafter, NNCC enlisted advertising firms and artists to further refine messages that were culturally relevant and sensitive to local realities. NNCC and advertising firms identified characters, slogans, themes, and expressions that would be visually appealing. Message branding included a shared color palette, layout, and logo to ensure consistency across provinces and to set the stage for a national communications campaign. NNCC then developed and aired TV spots covering a broad variety of topics, including diet, WASH, and other caregiving practices.

Public service announcements (PSAs) were developed by the government then tested in the field. Field tests demonstrated the PSAs were successful-as measured by message recall and comprehension. However, with the encouragement of MCA-Indonesia, NNCC developed a new PSA to avoid over-saturation of existing messages. Specifically, to counter challenges with some of the complex, less emotionally-engaging messages, NNCC developed and aired goofy, humor-filled spots-for example, on toilets and poop-to generate excitement about the topic and to encourage behavior change. There was widespread agreement among the priority populations that the humorous PSAs (latrine use) were more popular. In the case of the first PSA about feeding frequently and responsively, the complex nature of the message proved problematic for media production teams, frontline health workers, informal community leaders, and health facility workers.

NNCC also developed and disseminated simple materials (flip charts, flash cards, and flannel boards) that were designed to improve the adoption of a few behaviors known to reduce stunting. Additionally, NNCC strengthened community health worker and health facility worker capacity to deliver fewer messages through more focused training and mentoring.

Key Recommendations. Governments and other implementing organizations should consider adapting messages from other large-scale nutrition campaigns, based on findings from local, formative research. Messages should be pre-tested extensively, as NNCC did. NNCC reduced the many behaviors it could have fo- 
cused on and arrived at a much shorter and more manageable list. Campaign staff should also consider using messages that are humor-filled and emotionally engaging, even if such messages do not convey extensive technical information about a particular behavior.

\subsection{Utilizing Media}

A final challenge is that campaigns often rely on only one or two media channels, messages might not reach large segments of the population and may be insufficient to change behaviors. The use of social media to extend the campaign's reach and reinforce messaging from other sources is a useful practice.

Media extends the reach of messages across disperse populations. This is certainly beneficial to Indonesia which includes a population of 261 million residents scattered across 17,000 islands and 75,000 villages. Media, including social media, can strengthen the role of frontline health workers as well by reinforcing their status as experts and depicting them as educated, trusted, and available. Additionally, given the widespread lack of knowledge about stunting, the use of multiple channels can extend campaign coverage and more effectively encourage behavior change.

NNCC used a variety of media channels to increase community members' knowledge of stunting, change norms, and encourage the adoption of behaviors known to be associated with undernutrition. Media included a large mass media campaign, mid-sized media (local radio, opinion editorials), small media (banners, infographics, interactive photos), and social media (Facebook, Twitter, Instagram, and YouTube). Interpersonal communication and community and social mobilization complemented NNCC's media campaigns.

NNCC's campaign relied heavily on television spots because the cost per contact was low and therefore, more efficient. With respect to mid-sized media, NNCC developed and implemented a community radio campaign to reach populations with limited or no access to other media channels. NNCC's work with the press has already been noted. Interpersonal communication included capitalizing on existing services such as Maternal and Neonatal Health Services, WASH interventions, the Diarrheal Diseases Disorders Prevention and Management program, Integrated Management of Childhood Illnesses, and Family Planning and Reproductive Health Services, as well as mothers' groups and health post activation to reach individual women.

Social media constituted a major portion of NNCC's overall campaign. NNCC invested in Facebook ads to increase traffic on its Facebook page (GiziTinggi). Twitter and Instagram were important aspects of NNCC's social media strategy as well. While these platforms were more popular among young, urban audiences, a number of government decision-makers, including high-level officials from the $\mathrm{MOH}$, used Twitter to engage their audiences in dialogue about a range of topics. NNCC also conducted quick research to identify nutrition issues of interest to internet users. Furthermore, NNCC utilized Search Engine Optimiza- 
tion to track trending issues to better develop digital content.

Initially, NNCC's campaign was more effective in easier-to-reach sub-districts where the prevalence of stunting was low. High viewership ratings for YouTube ads and web advertorials showed a genuine interest in stunting. NNCC developed broadcast content continuously and created a large number of stories while simultaneously ensuring quality. NNCC also linked the content of its Facebook page to other social media, including Twitter, Instagram, and YouTube as well as other Facebook pages with similar content. Lastly, NNCC promoted social media in "off-air" activities such as district level advocacy events, one-on-one counselling, and mother-to-mother support groups. Each of these activities was important to countering the lack of information about stunting, its severity, and the consequences of not addressing it.

Key Recommendations. The use of social media was appropriate in Indonesia because: 1) it is extremely popular; 2) it is cost effective; and 3) it extends program reach to rural areas where social media can complement interpersonal communications interventions. However, if social media are used, governments and NGOs should consider capitalizing on other media channels as well. For example, multiple media channels linked to each other and to other websites with similar content can reinforce messages. Implementing organizations should also ensure that social media complements other SBCC interventions. NNCC found that while social media made it easy to improve norms and increase knowledge in easy-to-reach sub-districts, in less accessible regions, social media alone was not sufficient. To address this limitation, NNCC provided incentives to midwives and volunteers to conduct home visits and to follow-up by phone. Utilizing midwives and volunteers, including through phone calls to mothers, removed some of the financial barriers that kept service providers from carrying out home-based counselling. Elsewhere, similar programs might incorporate phones and other inexpensive outreach into their communications strategy.

\section{Discussion}

When policy makers and program planners, implementers, and evaluators lack information about programming challenges, they may fail to learn from the mistakes of others and are less capable of designing and implementing effective campaigns. Our experiences, along with those of others who have implemented similar campaigns, are summarized below.

\subsection{Engaging Stakeholders}

Haddad and Acosta [19] note that there are many reasons governments fail to prioritize stunting, including lack of exposure to nutrition in general, competing commitments, doubts about the efficacy of interventions, and so on. Others [20] [21] point out that all but the most extreme manifestations of undernutrition have no visible symptoms. Consequently, stunting is open to neglect [22]. In Indonesia, the government's failure to prioritize stunting was due, in part, to a 
lack of understanding of the concept and its importance for human development.

However, well-designed, targeted communication campaigns can help national, provincial, and community leaders design and enact policies that have a positive impact on nutrition [22] [23]. NNCC fully incorporated stakeholders into campaign design and implementation, thus ensuring broad-based support for stunting reduction efforts. To foster stakeholder engagement, NNCC worked within the parameters of existing government policies and programs, collaborated with multiple ministries at the district level, established steering committees headed by local government officials, helped develop coherent policies and frameworks that committed politicians to nutrition action, and engaged stakeholders in a variety of monitoring, evaluation, and dissemination initiatives. When stakeholders were involved in all aspects of the campaign, public awareness increased, as did demand for government services aimed at reducing stunting. Government staff from non-health sectors were able to understand the impact of nutrition on social, economic, cognitive, and physical development. The Alive \& Thrive project's experience in Bangladesh is similarly positive: when Alive \& Thrive used IYCF advocacy videos, met with national stakeholder alliances under the Government of Bangladesh, disseminated government-branded materials to implementing stakeholders, and spoke individually with government decision-makers and donors, local, regional, and national stakeholders committed themselves to reducing stunting [23]. However, others report only short-term gains. For example, in Bolivia, as part of the Zero Malnutrition campaign, stakeholder "champions" for nutrition initiated the decision-making process, secured resources, and routinized the administration of services; but they were not able to translate national policies into local actions [24]. Specifically, the campaign found it challenging to engage stakeholders outside the Ministry of Health because existing sectoral programs competed for non-health Ministry staff attention and few existing programs required collaboration across sectors [22]. Non-health Ministries did not understand why they should be involved in nutrition nor why existing resources should be re-directed toward stunting reduction [22]. High turnover of ministerial staff made it even more difficult to engage non-health sectors [22]. Additionally, differing perspectives regarding the nature of a problem and the most effective solutions to address it complicate policy formulation in a multi-stakeholder environment. In some situations, successful policy formulation may depend more upon the quality and acceptance of the decision-making process itself than the provision of empirical or technical evidence [25].

\subsection{Engaging Journalists}

NNCC found that engaging journalists in nutrition campaigns improved public opinion about stunting and positively influenced the policy-making decision process. NNCC worked with local journalists' associations to set the media agenda for stunting reduction, conducted media visits, participated in journal- 
ists' forums, and trained them. The resulting public attention to nutrition raised the visibility of stunting nationally. To the authors' knowledge, there are few nutrition campaigns in Indonesia or elsewhere that involve media beyond sharing news stories about nutrition, though there have been efforts to train journalists and involve them in other health promotion efforts, including HIV/AIDS [26]. In Bangladesh, Alive \& Thrive increased the commitment of stakeholders new to IYCF by engaging national associations of pediatricians, obstetricians, and gynecologists, donors, senior government officials, and journalists to raise awareness about stunting risks and to share information on what the government is doing to address it [23]. Alive \& Thrive also provided orientations and scholarships for journalists and diffused messages about stunting via TV talk shows and newspaper supplements. Gillespie and colleagues note that globally, there has been a surge in interest in malnutrition, with nearly every major development agency publishing policy documents about undernutrition [20]. Concomitantly, there have been large increases in spending for the reduction of malnutrition. Per Google Trends, "malnutrition" now matches "HIV/AIDS" in internet interest a phenomenon attributable in part to the food price spikes of 2007-08 which sparked greater media and policy interest in undernutrition.

\subsection{Adapting Messages}

Well designed, targeted communication campaigns can increase knowledge about stunting, resolve misconceptions, serve as cues to action, and demonstrate good nutrition, sanitation, and hygiene practices [23]. Often, epidemiological data and formative research are used to identify messages with the greatest potential to bring about behavior change [27] [28]. Key messages are usually few in number and should be motivational [28]. When NNCC relied on messages from other campaigns, even after conducting formative research to adapt them to the local context, those messages were not as effective as expected. Accordingly, NNCC de-emphasized such messages and instead, developed and aired goofy, humor-filled spots to generate excitement about a given topic and to encourage behavior change. One potential reason NNCC's earlier messages were less successful is that their priority population had difficulty processing information [28] [29]. Per the Elaboration Likelihood Model, receivers of information need to not only carefully scrutinize the message's arguments, but they must consider other issue-relevant material they have maintained in memory [29]. Additionally, receivers may be required to determine whether the source of the message is attractive and likeable [29]. Scrutinizing a message's arguments may have been particularly challenging in a population with low literacy. Conversely, determining whether the message was attractive may have been relatively easy for the priority population. As has been observed in the corporate world, markets are not about messages, but about conversations [30]. Per Levine and colleagues, corporate messaging is generally not funny nor interesting; it does not know who consumers are nor does it care [30]. NNCC's more traditional messages, 
designed to impart information, did not produce a great deal of conversation; however, its fun-filled messages generated a buzz.

\subsection{Utilizing Media}

Mass media offer advantages over other behavior change strategies, including greater reach, increased control over message content and delivery, consistency of messages, and low cost per person exposed [23]. However, as Hanna and Crittenden note, while media campaigns extend reach, when used alone, they are not always effective in garnering attention [31]. To both capture attention and engage individuals, traditional and social media are often required [31]. We found that NNCC's use of social media-including Facebook, Twitter, Instagram, and YouTube-not only extended the campaign's reach, but it also reinforced messaging from other sources, including interpersonal communication when mothers were reminded what they had already heard and seen through $\mathrm{TV}$, radio, and social media. In addition to connecting traditional and social media, NNCC's social media sites were connected to each other and to other internet sites. Even so, a well-designed communications campaign cannot solve every health challenge [23]. Potential challenges with mass media include the difficulty of capturing audience attention in a cluttered media environment, one-way flow of information, and the inability to tailor messages to individual needs. Thus, mass media should be considered one of many strategies that might be selected based on context [23].

\section{Conclusions}

NNCC's experience designing and implementing a media campaign, combined with insights from other campaigns, can guide the development of similar media interventions. First, to promote the success and sustainability of nutrition campaigns, implementing partners should ensure that their work is consistent with large-scale government policies and programs. Implementing partners should also consider strengthening committees under the leadership of local government and capitalize on participatory approaches to involve all stakeholders. Understanding the decision-making process up front may be more important in guaranteeing successful policy formation than providing empirical or technical evidence. Second, prior to selecting a strategy for working with journalists, governments and NGOs, implementers should undertake landscape analyses to determine whether using the approaches we describe is applicable. Engaging stakeholders new to IYCF offers the opportunity to raise awareness about stunting risks and to share information on what the government is doing to address it. Third, adapting nutrition messages used successfully in other large-scale campaigns, even if the process for doing so is comprehensive, may not always work. Implementing agencies should pre-test messages frequently and be willing to replace those that do not generate a conversation about the topic. Fourth, governments and other implementing organizations should consider combining 
traditional and social media where the use of social media is high and where formative research suggests individuals are likely to consult it for information on stunting and other health issues. However, social media should complement, not replace, other SBCC interventions. While media can play a role in raising the visibility of stunting, a one-size-fits-all approach across different geographies is not likely to work.

On-going process evaluations are needed to identify bottlenecks in the implementation of large-scale media campaigns and operations research should be used to test solutions to those bottlenecks. In the case of NNCC, earlier pre-testing and process evaluations might have identified challenges with the use of "standard" nutrition messages and operations research could have facilitated the testing of alternative approaches to garnering public enthusiasm for those approaches. Governments and other implementing organizations should consider rigorously executed randomized intervention trials and other study designs to assess the impact of various campaign components on community knowledge, attitudes, and practices related to nutrition.

\section{Funding}

This work was supported by the Millennium Challenge Account-Indonesia and IMA World Health.

\section{Author's Contributions}

$\mathrm{CH}, \mathrm{BC}, \mathrm{JW}, \mathrm{KD}, \mathrm{ST}$, and $\mathrm{ML}$ were major contributors to the writing of this manuscript. $\mathrm{CB}, \mathrm{MH}$, and SA provided significant programmatic details and key recommendations for practice.

\section{Conflicts of Interest}

The authors declare no conflicts of interest regarding the publication of this paper.

\section{References}

[1] Black, R.E., Allen, L.H., Bhutta, Z.A., Caulfield, L.E., de Onis, M., Ezzati, M., et al. (2008) Maternal and Child Undernutrition: Global and Regional Exposures and Health Consequences. Lancet, 371, 243-260. https://doi.org/10.1016/S0140-6736(07)61690-0

[2] De Onis, M. and Branca, F. (2016) Childhood Stunting: A Global Perspective. Maternal and Childhood Nutrition, 12, 12-26. https://doi.org/10.1111/mcn.12231

[3] UNICEF, World Bank, \& World Health Organization (2017) Levels and Trends in Child Malnutrition; UNICEF, WHO, World Bank Group Joint Child Malnutrition Estimates: Key Findings of the 2017 Edition. New York, NY.

[4] Bhutta, Z.A., Das, J.K., Rizvi, A., et al. (2013) The Lancet Nutrition Interventions Review Group, and the Maternal and Child Nutrition Study Group. Evidence-Based Interventions for Improvement of Maternal and Child Nutrition: What Can Be Done and at What Cost? Lancet, 382, 452-477. 
https://doi.org/10.1016/S0140-6736(13)60996-4

[5] Black, R.E., Morris, S.S. and Bryce, J. (2013) Where and Why Are 10 Million Children Dying Every Year? Lancet, 361, 2226-2234.

https://doi.org/10.1016/S0140-6736(03)13779-8

[6] Humphries, D.L., Dearden, K.A., Crookston, B.T., et al. (2015) Cross-Sectional and Longitudinal Associations Between Household Food Security and Child Anthropometry at Ages 5 and 8 Years in Ethiopia, India, Peru, and Vietnam. Journal of Nutrition, 145, 1924-1933. https://doi.org/10.3945/jn.115.210229

[7] National Institute of Research and Development, Ministry of Health (2013) Basic Health Research Survey (Risetkesehatandasar). National Institute of Research and Development, Ministry of Health, Jakarta.

[8] Arimond, M. and Ruel, M.T. (2004) Dietary Diversity is Associated with Child Nutritional Status: Evidence from 11 Demographic and Health Surveys. Journal of $\mathrm{Nu}$ trition, 134, 2579-2585. https://doi.org/10.1093/jn/134.10.2579

[9] Dewey, K.G. and Adu-Afarwah, S. (2010) Systematic Review of the Efficacy and Effectiveness of Complementary Feeding Interventions in Developing Countries. $\mathrm{Ma}$ ternal and Childhood Nutrition, 4, 24-85. https://doi.org/10.1111/j.1740-8709.2007.00124.x

[10] Humphrey, J.H. (2009) Child Undernutrition, Tropical Enteropathy, Toilets, and Handwashing. Lancet, 374, 1032-1035.

https://doi.org/10.1016/S0140-6736(09)60950-8

[11] Esrey, S.A. (1996) Water, Waste and Well-Being: A Multicountry Study. American Journal of Epidemiology, 143, 608-623. https://doi.org/10.1093/oxfordjournals.aje.a008791

[12] Dangour, A.D., Watson, L., Cumming, O., et al. (2013) The Effect of Interventions to Improve Water Quality and Supply, Provide Sanitation and Promote Handwashing with Soap on Physical Growth in Children. Cochrane Database of Systematic Reviews, 8, CD009382.

[13] Naugle, D.A. and Hornik, R.C. (2014) Systematic Review of the Effectiveness of Mass Media Interventions for Child Survival in Low- and Middle-Income Countries. Journal of Health Communication: International Perspectives, 19, 190-215. https://doi.org/10.1080/10810730.2014.918217

[14] Asian Development Bank (2017) Asian Development Outlook, 2017: Transcending the Middle-Income Challenge. Manila, Philippines.

[15] Trading Economics. Indonesia GDP Annual Growth Rate 2017. https://tradingeconomics.com/indonesia/gdp-growth-annual

[16] Indonesia Population. http://worldpopulationreview.com/countries/indonesia-population/

[17] Rastogi, V., Tamboto, E., Tong, D. and Sinburimsit, T. (2013) Indonesia's Rising Middle-Class and Affluent Consumers: Asia's Next Big Opportunity. https://www.bcgperspectives.com/content/articles/center_consumer_customer_insi ght_consumer_products_indonesias_rising_middle_class_affluent_consumers/

[18] Friedman, J., Heywood, P.F., Marks, G., Saadah, F. and Choi, Y. (2007) Health Sector Decentralization and Indonesia's Nutrition Programs: Opportunities and Challenges. World Bank Working Paper Number 39690, World Bank, Washington DC.

[19] Haddad, L. and Acosta, A.M. (2012) Accelerating Reductions in Undernutrition: What Can Nutrition Governance Tell Us? Institute of Development Studies in Focus Policy Briefing, Number 22, Institute of Development Studies, Brighton. 
[20] Gillespie, S., Haddad, L., Mannar, V., Menon, P., Nisbett, N. and the Maternal and Child Nutrition Study Group (2013) The Politics of Reducing Malnutrition: Building Commitment and Accelerating Progress. The Lancet, 392, 552-569. https://doi.org/10.1016/S0140-6736(13)60842-9

[21] Victora, C.G., Barros, F.C., Assunção, M.C., Restreo-Mendez, M.C., Matijasevich, A. and Martorell, R. (2012) Scaling Up Maternal Nutrition Programs to Improve Birth Outcomes: A Review of Implementation Issues. Food and Nutrition Bulletin, 33, S6-S26. https://doi.org/10.1177/15648265120332S102

[22] Hoey, L. and Pelletier, D.L. (2011) Bolivia's Multisectoral Zero Malnutrition Program: Insights on Commitment, Collaboration, and Capacities. Food and Nutrition Bulletin, 32, S70-S81.

[23] Sanghvi, T., Haque, R., Roy, S., et al. (2016) Achieving Behavior Change at Scale: Alive \& Thrive's Infant and Young Child Feeding Programme in Bangladesh. Food and Nutrition Bulletin, 12, 141-54.

[24] Field, J.O. (1977) The Soft Underbelly of an Applied Knowledge: Conceptual and Operational Problems in Nutrition Planning. Food Policy, 2, 228-239.

https://doi.org/10.1016/0306-9192(77)90082-3

[25] Hill, R., Gonzalez, W. and Pelletier, D.L. (2011) The Formulation of Consensus on Nutrition Policy: Policy Actors' Perspectives on Good Process. Food and Nutrition Bulletin, 32, S92-S104. https://doi.org/10.1177/15648265110322S206

[26] Martinez-Cajas, J.L., Invernizzi, C.F., Ntemgwa, M., Schader, S.M. and Wainberg, M.A. (2008) The Impact of the Journalist-to-Journalist Program on Worldwide HIV Awareness. AIDS, 22, 1687-1688. https://doi.org/10.1097/QAD.0b013e328308de21

[27] Fabrizio, C.S., van Liere, M. and Pelto, G. (2014) Identifying Determinants of Effective Complementary Feeding Behavior Change Interventions in Developing Countries. Maternal and Childhood Nutrition, 10, 575-592. https://doi.org/10.1111/mcn.12119

[28] Lutter, C.K., Iannotti, L., Creed-Kanashiro, H., et al. (2013) Key Principles to Improve Programmes and Interventions in Complementary Feeding. Maternal and Childhood Nutrition, 9, 101-115. https://doi.org/10.1111/mcn.12087

[29] Wilson, B.J. (2007) Designing Media Messages about Health and Nutrition: What Strategies Are Most Effective? Journal of Nutrition Education and Behavior, 39, S13-S19. https://doi.org/10.1016/j.jneb.2006.09.001

[30] Levine, R., Locke, C., Searle, D. and Weinberger, D. (2001) The Cluetrain Manifesto: The End of Business as Usual. Basic Books, New York.

[31] Hanna, R., Rohm, A. and Crittenden, V.L. (2011) We're All Connected: The Power of the Social Media Ecosystem. Business Horizons, 54, 265-273. https://doi.org/10.1016/j.bushor.2011.01.007 